Endocrinol. Japon. 1984, 31 (1), 63-70

\title{
A Case of Calcitonin Producing Adenoma of the Thyroid
}

\author{
Takaya KODAMA, Masako TAMURA, Yoshiharu KANAJI, \\ YUKIO ITO, TAKaO OBARA, YoSHIHIDE FUJIMOTO \\ AND AKIRA HIRAYAMA* \\ Department of Endocrine Surgery and Department of Surgical Pathology*, \\ Tokyo Women's Medical College. \\ Ichigaya-Kawadacho, Shinjuku-ku, Tokyo 162
}

\begin{abstract}
A thyroid tumor about $4 \mathrm{~cm}$ in diameter was removed from a 53-year-old female. The clinical features were those of common thyroid adenomas, such as soft, smooth-surfaced and round contour of the tumor, no calcification and no lymph node metastasis. However, microscopically, the tumor was composed of compact cell nests rather similar to paraganglioma without any follicle formation. Histochemical examination revealed its $\mathrm{C}$-cell nature, such as argyrophilia and calcitonin activity, although no amyloid deposit was demonstrated. Extremely high levels of calcitonin were found in the stored serum taken pre-operatively, but serum carcinoembryonic antigen levels were within normal limits. The calcitonin level dropped to the normal range soon after the operation, indicating the absence of residual tumorous tissues. Thus, the tumor behaves as an adenoma with a C-cell nature. Interestingly enough, the benign counterpart of medullary carcinoma of the thyroid seems to be quite rare in humans, and no similar tumors have ever been reported. Variations of C-cell tumors will be discussed in relation to their production and secretion of carcinoembryonic antigen.
\end{abstract}

Medullary carcinoma of the thyroid (MCT) was first regarded as a clinical entity by Hazard et al. (1959), recognizing a group of solid non-follicular tumors with comparatively good prognosis among apparently undifferentiated carcinomas. The C-cell or parafollicular cell of the thyroid was suggested as the origin of MCT by Williams (1966a). The C-cell belongs to the category of so-called APUD (amine precursor uptake and decarboxylation) cell series. MCT and the C-cell were found to share common unique biological characteristics, such as the production of various kinds of polypeptide

Received December 6, 1983 hormones, confirming the $\mathrm{C}$-cell as the origin of MCT.

A wide variation of morphological futures and prognosis of MCT had already been pointed out by Williams et al. (1966b), and even some anaplastic carcinomas were found to be of a C-cell nature (Kruseman et al., 1982). However, recent reports disclosed new aspects of MCT, which lie beyond the scope of mere variation. Firstly, some MCT are thyroid hormone-dependent (Wahner et al., 1968 ; Didolkar and Moore, 1974 ; Hales et al., 1982). Secondly, some possible MCT not only have a follicular pattern but also produce thyroglobulin (Valenta et al., 1977 ; Hales et al., 1982; Pfaltz et al., 1983; 
Ljungberg et al., 1983). Furthermore, MCT with mucus production is reported (Fernandes et al., 1982). Thirdly, Kameda et al. (1978, 1979) found a thyroglobulin-like substance (C-Thyroglobulin) in the C-cells and also in MCT. Calmettes et al. (1982) reported thyroid carcinomas with a poorly differentiated follicular pattern, which produced calcitonin (CT) and carcinoembryonic antigen (CEA), proposing these carcinomas as a new clinical entity. Consequently, the concept that the C-cell and MCT are derived from the neural crest and quite different from the follicular epithelial cells seems to be not so valid.

Another enigma of $\mathrm{MCT}$ is the rarity of its benign counterpart, i.e., $\mathrm{C}$-cell adenoma. In rats, C-cell hyperplasia, C-cell adenoma (or focal C-cell hyperplasia), and C-cell carcinomas are not infrequently observed, and their serial progression is estimated (Boorman and DeLellis, 1983). In humans, nodule formation of C-cells is occasionally found in the normal thyroid (Gibson et al., 1981), and even C-cell hyperplasia has been observed in the thyroid tissue of familial MCT cases (Wolfe et al., 1973). But to the best of our knowledge, no C-cell adenoma, certainly not a large one, has ever been reported. The tumors reported as C-cell adenomas by Beskid et al. (1971) seem to be hardly acceptable as genuine ones, becase of the lack of any substantial proof.

Elevation of not only serum CT but also CEA levels in MCT was first reported by Ishikawa and Hamada (1976) and Hamada et al. (1976), and well confirmed by others (Calmettes et al., 1978; Kodama et al., 1979). CEA was also identified in the C-cell of the normal thyroid (Kodama et al., 1980) and proved to be a useful marker of nontumorous and tumorous C-cells. Of interest is the report of Rougier et al. (1983) that CEA is a more meaningful tumor marker capable of defining a high-risk subgroup than $\mathrm{CT}$, although the latter seems to be more sensitive than the former in detecting
MCT.

We report a case of unique thyroid tumor, which may be interpreted as a C-cell adenoma, or, to say the least, as a most clearly differentiated type of MCT. Discussion will be concerned with the standpoint of CEA production and biological differentiation of MCT.

\section{Case Report}

A 53-year-old female patient visited our clinic on March 22, 1983, complaining of a tumor of five months' duration in the left thyroid region. The tumor was soft, round, smooth-surfaced, well movable and about 4 $\mathrm{cm}$ in diameter. Concomitantly, another tumor, measuring $1.5 \times 1.2 \mathrm{~cm}$, was found in the right parotid region. It proved to be an adenolymphoma after operation, but this was not a matter of concern in the study. There was no personal or family history of any other endocrine disorders. Thyroid function tests were within normal limits. The tumor exhibited no calcification on the soft X-ray film of the neck. By ultrasound sonography, it was found to be homogeneously solid and well demarcated from the surrounding thyroid tissues. She was admitted to our hospital on April 26 for surgical excision of the thyroid and parotid tumors. Routine laboratory studies revealed no abnormalities. Left lobectomy of the thyroid (and resection of the superficial lobe of the right parotid gland) was performed on May 2, under the diagnosis of a follicular adenoma without any complications. After the thyroid tumor was proved to be of $\mathrm{C}$-cell nature, urinary catecholamines and their metabolites were assayed, considering the possibility of Sipple's syndrome, i.e., association of pheochromocytomas, but they were normal and computed tomography revealed no adrenal mass lesions. The post-operative course was uneventful, and the patient was discharged from the hospital on May 16. She was last seen at 
the out-patient clinic on November 1, without evidence of recurrent disease.

\section{Materials and Methods}

The surgical material was fixed in $10 \%$ formalin, routinely processed, embedded in paraffin, and sectioned into $4 \mu$ in thicknesses. All sections were stained with hematoxylin and eosin (HE), Masson trichrome, periodic acid Schiff (PAS), Elastica van Gieson, Congo red and Grimelius' silver impregnation method.

Immunohistochemical studies were performed by peroxidase anti-peroxidase (PAP) method for the presence of $\mathrm{CT}$, CEA, ACTH, somatostatin, glucagon and thyroglobulin, using Dako PAP kits. For confirmation of the presence of CT and CEA, other anti-CT and -CEA antiserum were also applied, which were commercially available from Ortho Diagnostic System Inc., Roritan, NJ, USA.

Measurement of serum CT and CEA by radioimmunoassay was performed in the Mitsubishiyuka Laboratory of Medical Science Co., Tokyo, the normal range being less than 200 $\mathrm{pg} / \mathrm{ml}$ and $2.5 \mathrm{ng} / \mathrm{ml}$, respectively.

\section{Results}

\section{Gross findings}

The tumor situated at the upper portion of the left thyroid lobe, being apparently encapsulated and measuring $4 \mathrm{~cm}$ in diameter. On the cut surface, brown to gray tumor tissue stood up above the rim with a very thin capsule (Fig. 1). It was indistinguishable from a common microfollicular adenoma.

\section{Microscopical findings}

The tumor was composed of compact cell nests with no follicle formation. The cells were uniform and medium-sized, having

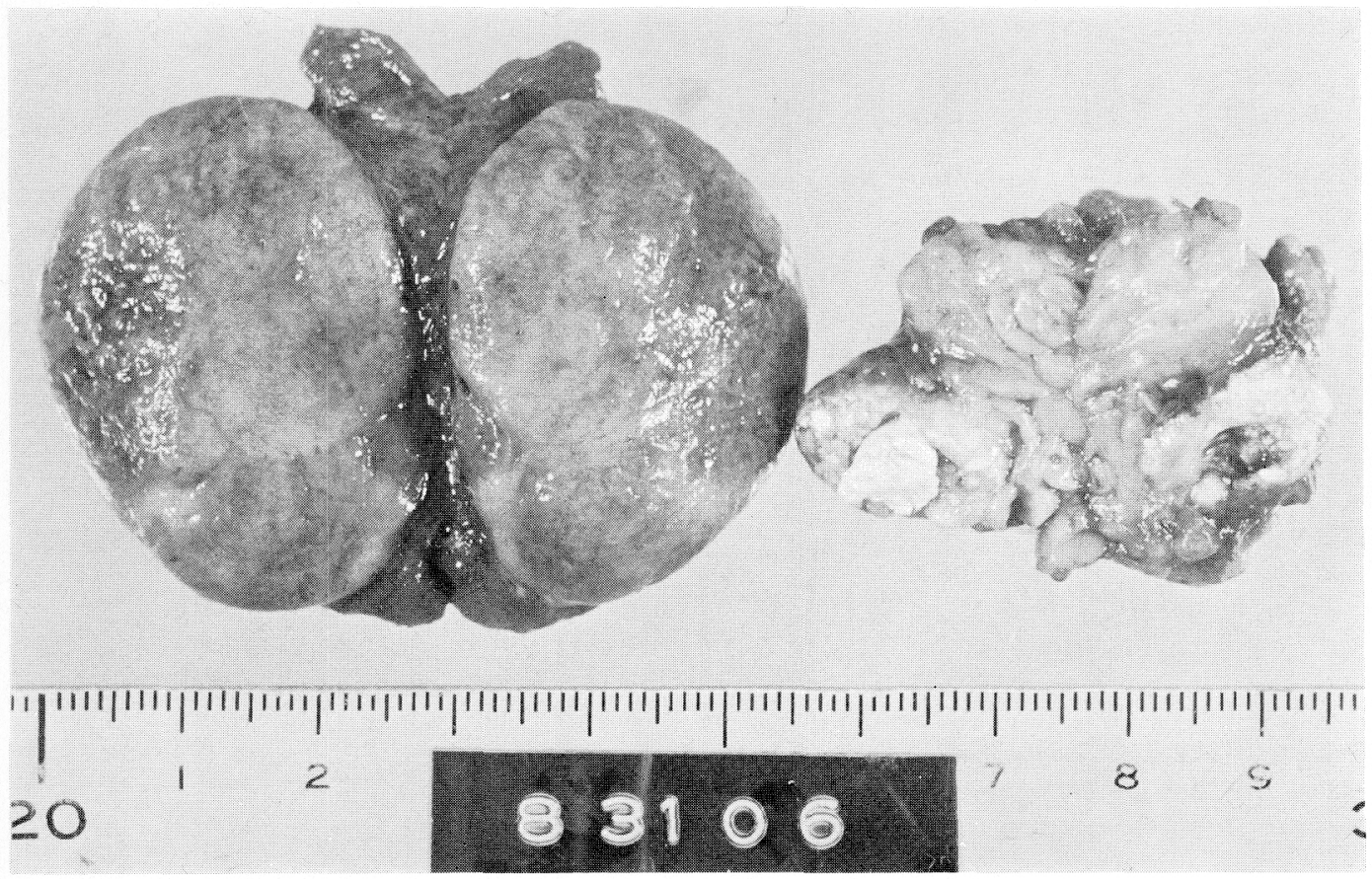

Fig. 1. Cut surfaces of the resected specimens, thyroid tumor, left, and parotid tumor, right. The thyroid tumor is well demarcated from the surrounding thyroid tissue, glistening and gray to brown in color, and protrudes markedly above the rim. 


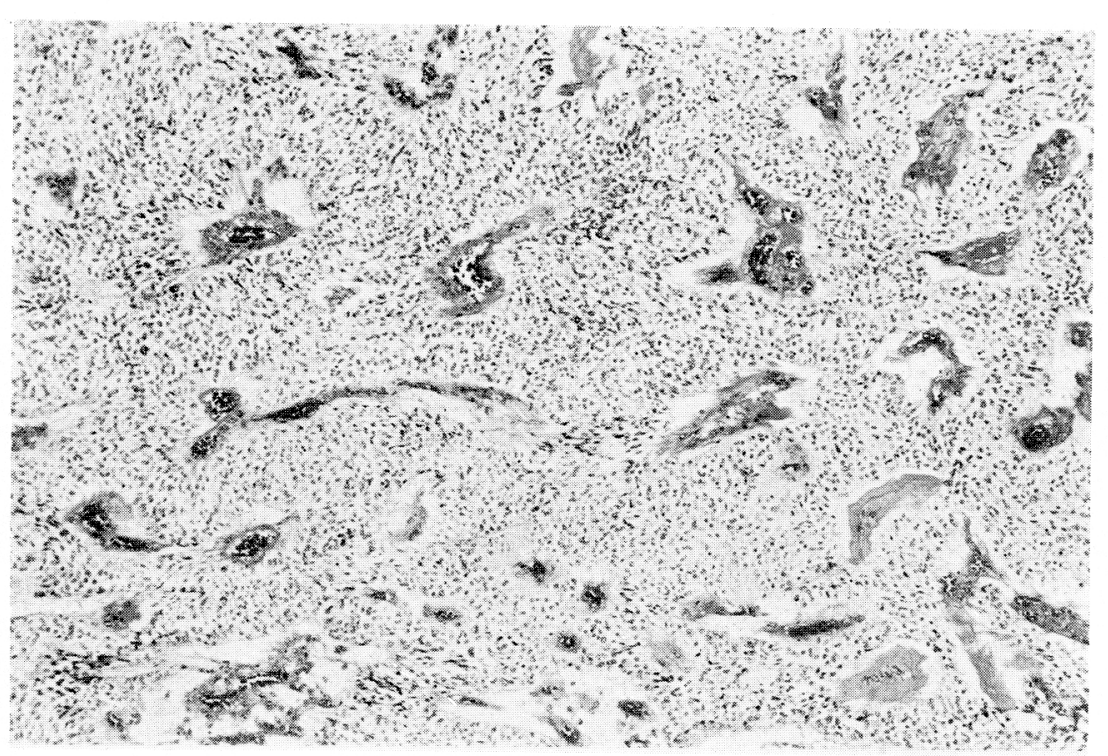

Fig. 2. Microscopical features of the thyroid tumor. The capillaries are enormously rich, and fusiform cells are arrayed in radial fashion around them. Hematoxylin and eosin, $\times 90$.

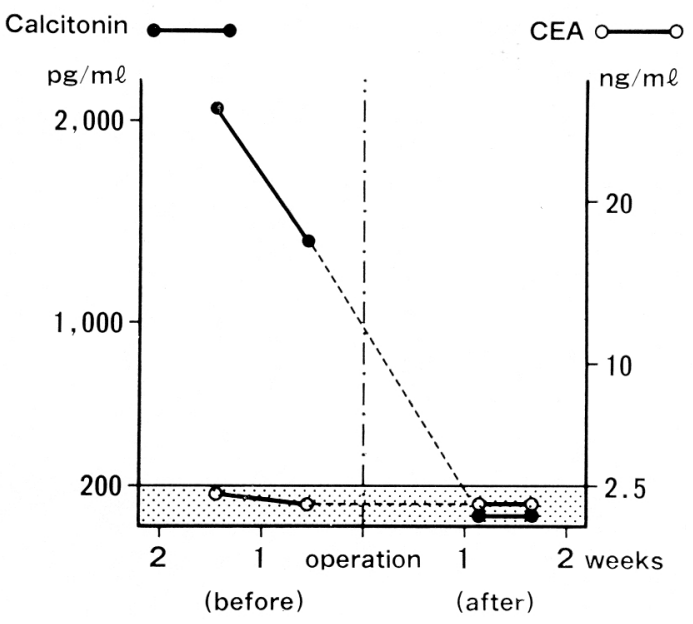

Fig. 3. Serum CT and CEA levels before and after operation. Note the abrupt decrease in serum CT after operation in contrast with serum CEA, which is constantly low during the course. Dotted area denotes the normal range for both serum $\mathrm{CT}$ and CEA. fusiform or cuboidal acidphilic cytoplasm and comparatively small elliptical nucleus. Mitotic figures were scarcely observed. It was enormously rich in the small vessels and the capillaries, around which fusiform cells were arrayed in radial fashion (Fig. 2). No abnormalities were found in the neighboring thyroid tissues. Encapsulation of the tumor was incomplete, without even thin fibrous capsule depending on the location, but neither infiltrative growth nor vascular invasion was observed.

\section{Radioimmunoassay of serum $C T$ and $C E A$}

The exact nature of the tumor was not clear only from the microscopical findings, but extremely high levels of CT, i.e., 2065 and $1420 \mathrm{pg} / \mathrm{ml}$, were found in the stored serum taken pre-operatively. The serum level of CT decreased down to the normal range soon after the operation. Serum CEA levels were less than $2.5 \mathrm{ng} / \mathrm{ml}$, pre-and post-operatively (Fig. 3). Serum CT and CEA remained low, being $19 \mathrm{pg} / \mathrm{ml}$ and 2.1 $\mathrm{ng} / \mathrm{ml}$ respectively, at the last visit to the out-patient clinic, about five months after the operation. 
Histochemical and immunohistochemical studies

Amyloid deposition was not demonstrated in the tumor tissue, but the tumor cells proved to be argyrophil (Fig. 4). The tumor cells were found to contain CT (Fig. 5), but no other polypeptide hormones, such as glucagon, somatostatin and ACTH. Contrary to expectation, CEA was also positive (Fig.
6). Thyroglobulin was negative, and its presence was demonstrated only in the nontumorous follicles left around the periphery of the tumor and small cell clusters in the vicinity of these follicles (Fig. 7).
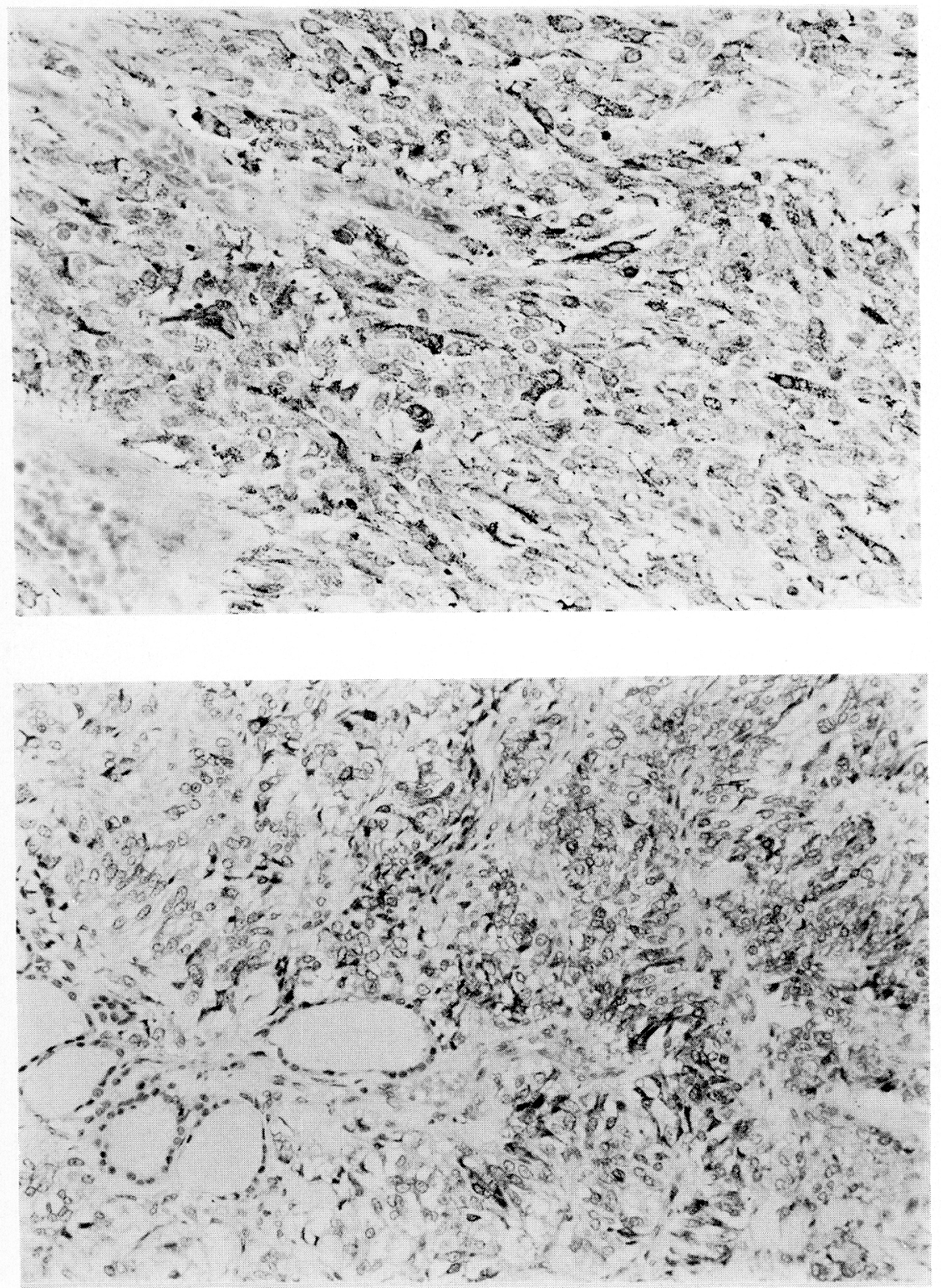

Fig. 4. Most of the tumor cells are more or less argyrophil. Grimelius' silver impregnation method, $\times 360$.
Fig. 5. PAP staining for CT. CT activities of the tumor cells vary from cell to cell. The normal follicular cells left in the tumorous tissues are negative for CT. $\times 180$. 


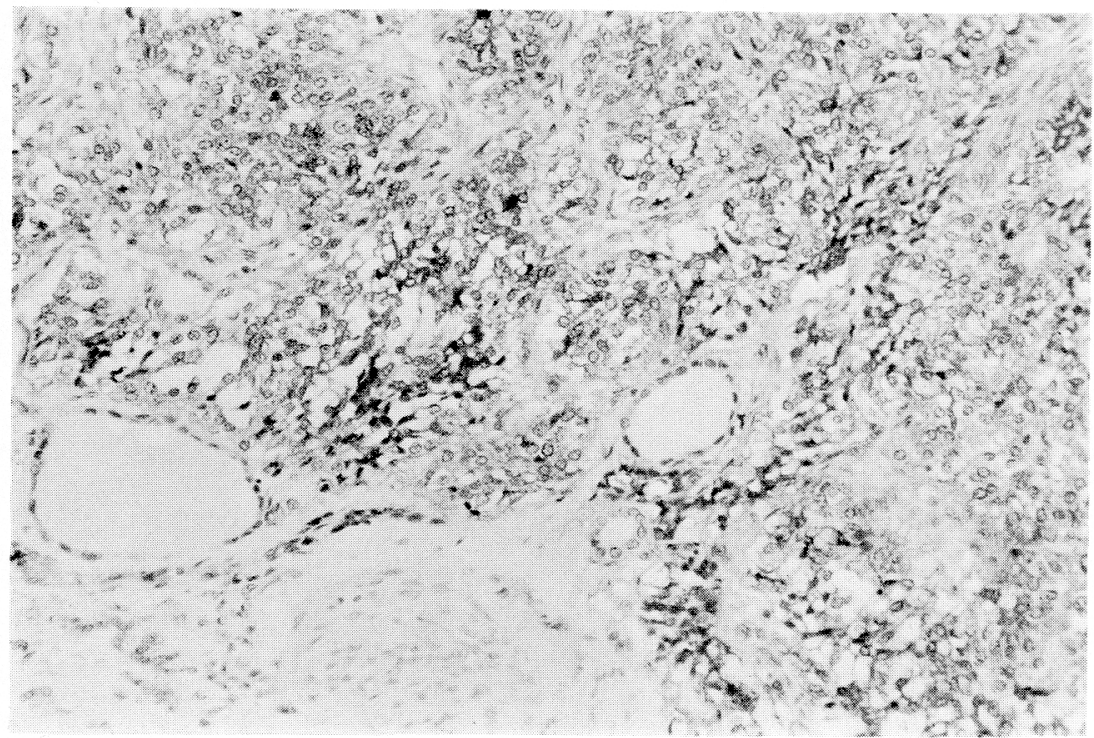

Fig. 6. PAP staining for CEA. CEA activities are found in the tumorous tissues more diffusely than CT without intracellular polarity. The normal follicular cells left in the tumorous tissues are negative for CEA. $\times 180$.

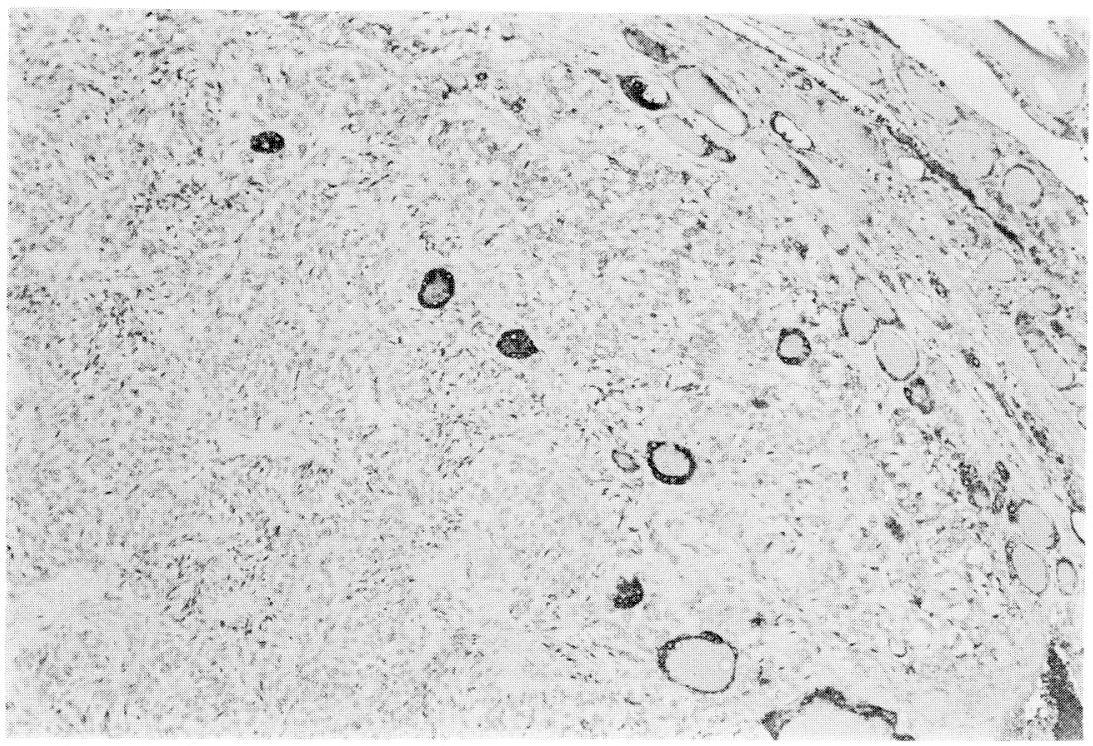

Fig. 7. PAP staining for thyroglobulin. The tumor cells are negative. Thyroglobulin activities are found only in the surrounding thyroid tissues and the follicular cells left in the periphery of the tumor. Note the absence of true capsule. $\times 90$.

\section{Discussion}

This tumor seems to be grouped into the category of MCT from the standpoint of CT production, but it has many peculiar characteristics. Firstly, its clinical features are those of a common thyroid adenoma, such as soft, round and smooth-surfaced contour of the tumor, no calcification and no lymph node metastasis. An abrupt drop in serum CT levels clearly denotes that there are no residual tumorous tissue left behind after operation. Secondly, microscopical features are, so to say, more similar to paraganglioma of the thyroid (Buss et al., 
1980) than MCT, without any amyloid deposition. Thirdly, the serum CEA level was within normal limits.

Serum CEA is known to be sensitive enough to diagnose MCT, though the sensitivity may be somewhat less than that of CT. Accordingly, the normal serum CEA value of this patient with a tumor as large as $4 \mathrm{~cm}$ in diameter denotes, most logically, the possibility that this tumor produces CEA but dose not secrete it, at least in large amounts. MCT patients with high CEA values are reported to have a poorer prognosis than those with low CEA values (Rougier et al., 1981). The reverse may also be true, and the normal CEA value of this case is able to be interpreted as suggesting its benign nature.

Several kinds of polypeptide hormones other than CT were identified in MCT (Iwanaga et al., 1978; Kameya et al., 1983). Generally speaking, the multi-hormonal activities of endocrine tumors tend to suggest their malignant behavior. In this case, only CT activity was demonstrated, and this observation is also in favor of its benign nature.

From this study, no direct proof was obtained for or against the concept of the $\mathrm{C}$-cell as the exclusive origin of MCT. But, from many aspects already mentioned, this tumor may be interpreted as an C-cell adenoma, or to say the least, to represent most differentiated types of MCT, though differentiation between these is difficult at present. To the best of our knowledge, this type of tumor has not yet been reported, but it seems conceivable that these tumors have not been closely studied and are regarded only as eccentric adenomas.

\section{References}

Beskid, M., R. Lorenc and A. Rošciszewska (1971). C-cell thyroid adenoma in man. $J$. Pathol. 103, 1-4.

Boorman, G. A. and R. A. DeLellis (1983). Ccell hyperplasia, C-cell adenoma, Medullary carcinoma, thyroid, rat. In : Endocrine System (T. C. Jones, U. Mohr and R. D. Hund eds.), Springer-Verlag, Berlin, pp. 192-204.

Buss, D. H., R. B. Marshall, F. G. Baird R. T. Myers (1980). Paraganglioma of the thyroid gland. Am. J. Surg. Pathol. 4, 589-593.

Calmettes, C., M.S. Moukhtar and G. Milhaud (1978). Plasma carcinoembryonic antigen versus plasma calcitonin in the diagnosis of medullary carcinoma of the thyroid. Cancer Immunol. Immunother. 4, 251-256.

Calmettes, C., B. Caillou, M. S. Moukhtar, G. Milhaud and R. Gerard-Marchant (1982). Calcitonin and carcinoembryonic antigen in poorly differentiated follicular carcinoma. Cancer 49, 2342-2348.

Didolkar, M. S. and G. E. Moore (1974). Hormone-dependent medullary carcinoma of the thyroid. Am. J. Surg. 128, 100-102.

Fernandes, B. J., Y. C. Bedard and I. Rosen (1982). Mucus-producing medullary cell carcinoma of the thyroid gland. J. Clin. Pathol. 78, 536-540.

Gibson, W. C. H., T.-C. Peng and B. P. Croker (1981). C-cell nodules in adult human thyroid. Am. J. Clin. Pathol. 75, 347-350.

Hales, M., W. Rosenau, M. D. Okerlund and M. Galante (1982). Carcinoma of the thyroid with a mixed medullary and follicular pattern. Morphologic, immunohistochemical, and clinical laboratory studies. Cancer 50, 1352-1359.

Hamada, S., N. Ishikawa, M. Yoshii, S. Morita, M. Fukunaga, K. Torizuka and M. Fukase (1976). Roles of circulating carcinoembryonic antigen and calcitonin in diagnosis of medullary thyroid carcinoma: a comparative study. Endocrinol. Japon. 23, 505-510.

Hazard, J. B., W. A. Hawk and G. Crile (1959). Medullary (solid) carcinoma of the thyroid-A clinicopathologic entity. J. Clin. Endocrinol. Metab. 19, 152-161.

Ishikawa, N. and S. Hamada (1976). Association of medullary carcinoma of the thyroid with carcinoembryonic antigen. $B r . J$. Cancer 34, 111-115. 
Iwanaga, T., H. Koyama, S. Uchiyama, Y. Takahashi, S. Nakao, T. Itoh, T. Horai, A. Wada and R. Tateishi (1978). Production of several substances by medullary carcinoma of the thyroid. Cancer 41, 1106-1112.

Kameda, Y. and A. Ikeda (1978). Immunohistochemical study of a large molecular fragment of thyroglobulin in parafollicular cells. Cell Tiss. Res. 187, 429-428.

Kameda, Y., T. Harada, K. Ito and A. Ikeda (1979). Immunohistochemical study of the medullary thyroid carcinoma with reference to C-Thyroglobulin reaction of tumor cells. Cancer 44, 2071-2082.

Kameya, T., T. Bessho, M. Tsumuraya, K. Yamaguchi, K. Abe, Y. Shimosato and N. Yanaihara (1983). Production of gastrin releasing peptide by medullary carcinoma of the thyroid. Virchows Arch. [Pathol. Anat.] 401, 99-108.

Kodama, T., M. Fujino, Y. Endo, T. Obara, Y. Fujimoto, I. Adachi, K. Abe, T. Oda and T. Wada (1979). Family study of serum carcinoembryonic antigen in inherited medullary carcinoma of the thyroid. Cancer 44, 661664.

Kodama, T., M. Fujino, Y. Endo, T. Obara, Y. Fujimoto, T. Oda and T. Wada (1980). Identification of carcinoembryonic antigen in the C-cell of the normal thyroid. Cancer 45, 98-101.

Kruseman, A. C. N., F. T. Bosman, J. C. Van B. Henegow, G. Cramer-Knijnenburg and G. B. De La Riviere (1982). Medullary differentiation of anaplastic thyroid carcinoma. Am. J. Clin. Pathol. 77, 541-547.
Ljungberg, O., U.-B. Ericsson, L. Bondeson and J. Thorell (1983). A compound follicularparafollicular cell carcinoma of the thyroid: a new tumor entity? Cancer 52, 1053-1061.

Pfaltz, M., Chr. E. Hedinger and J. P. Mühlethaler (1983). Mixed medullary and follicular carcinoma of the thyroid. Virchows Arch. [Pathol. Anat. ] 400, 53-59.

Rougier, Ph., C. Calmettes, A. Laplanche, J. P. Travagli, M. Lefevre, C. Parmentier, G. Milhaud and M. Tubiana (1983). The values of calcitonin and carcinoembryonic antigen in the treatment and management of nonfamilial medullary thyroid carcinoma. Cancer 51, 855862.

Valenta, L. J., M. Michel-Bechet, J. C. Mattson and F.R. Singer (1977). Microfollicular thyroid carcinoma with amyloid rich stroma, resembling medullary carcinoma of the thyroid (MCT). Cancer 39, 1573-1586.

Wahner, H. W., C. Cuello and F. Aljure (1968). Hormone-induced regression of medullary (solid) thyroid carcinoma. Am. J. Med. 45, 789-794.

Williams, E. D. (1966a). Histogenesis of medullary carcinoma of the thyroid. J. Clin. Pathol. 19, 114-118.

Williams, E. D., C. L. Brown and I. Doniach (1966b). Pathological and clinical findings in a series of 67 cases of medullary carcinoma of the thyroid. J. Clin. Pathol. 19, 103-113.

Wolfe, H. J., K. E. W. Melvin, S. J. CerviSkinner, A. A. Al Saadi, J. F. Juliar, C. E. Jackson and A. H. Tashjian (1973). C-cell hyperplasia preceding medullary thyroid carcinoma. New Eng. J. Med. 289, 437-441. 